\title{
Proton-conductive nano zeolite-PVA composite film as a new water-absorbing electrolyte for water electrolysis
}

\author{
M. Nishihara ${ }^{1,2 *}$, Y. Terayama ${ }^{2}$, T. Haji ${ }^{3}$, S. M. Lyth ${ }^{2,4}$, S. Satokawa ${ }^{5}$, H. Matsumoto ${ }^{2,3}$ \\ ${ }^{1}$ Next-Generation Fuel Cell Research Center (NEXT-FC), Kyushu University, 744 Motooka, Nishi-ku, Fukuoka-shi, \\ 819-0395 Fukuoka, Japan \\ ${ }^{2}$ International Institute for Carbon-Neutral Energy Research (WPI-I2CNER), Kyushu University, 744 Motooka, Nishi-ku, \\ Fukuoka-shi, 819-0395 Fukuoka, Japan \\ ${ }^{3}$ Graduate School of Engineering, Kyushu University, 744 Motooka, Nishi-ku, Fukuoka-shi, 819-03955 Fukuoka, Japan \\ ${ }^{4}$ Energy 2050, Department of Mechanical Engineering, University of Sheffield, Sheffield S10 2TK, UK \\ ${ }^{5}$ Department of Materials and life science, Seikei University, 3-3-1 Kichijoji kita-machi, Musashino-shi, 180-8633 Tokyo, \\ Japan
}

Received 15 September 2017; accepted in revised form 2 November 2017

\begin{abstract}
In this study, organic-inorganic composite electrolyte membranes are developed for a novel water-absorbing porous electrolyte water electrolysis cell. As the materials of the composite electrolyte membrane, $80 \mathrm{wt} \%$ of a proton-conducting nano zeolite (H-MFI) as an electrolyte and $20 \mathrm{wt} \%$ of poly(vinyl alcohol) (PVA) as a cross-linkable matrix are used. The nano zeolite is prepared by a milling process. The nano zeolite-PVA composite membrane precursors are prepared by spraying onto a substrate, followed by cross-linking. The resulting nano zeolite-cross-linked PVA composite films are then evaluated for their properties such as proton conductivity as electrolyte membranes for the water-absorbing porous electrolyte water electrolysis cell. It is confirmed that conventional materials such as zeolites and PVA can be used for the water electrolysis as an electrolyte.
\end{abstract}

Keywords: polymer composites, water-absorbing porous electrolyte water electrolysis, zeolite, poly(vinyl alcohol), proton conductivity

\section{Introduction}

Effective storage and usage of renewable energy is required in order to bring about a large reduction in greenhouse gas emissions. However, the difficulty of effectively storing renewable energy has become one of the key technological hurdles in the popularization of renewable energy. One promising solution for the storage of renewable energy effectively is hydrogen energy [1-3]. In an ideal hydrogen energy economy, excess electricity generated from renewable energy would be converted to hydrogen using processes such as water electrolysis. This would be stored and/or transported, and then used in a fuel cell to produce electricity. A critical aspect of the establishment of the hydrogen economy is the development of effective hydrogen production via water electrolysis.

Water electrolysis is the most promising method for the production of hydrogen from renewable energy. There are three main types of electrochemical cell used to perform water electrolysis: alkaline water electrolyzers, solid oxide electrolysis cells, and polymer electrolyte membrane (PEM) type cells [4]. The PEM water electrolysis cells shown in Figure 1a have many attributes in common with polymer electrolyte fuel cells (PEFCs), and there are several advantages such as high energy density, and compact system

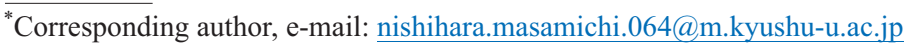
C BME-PT 


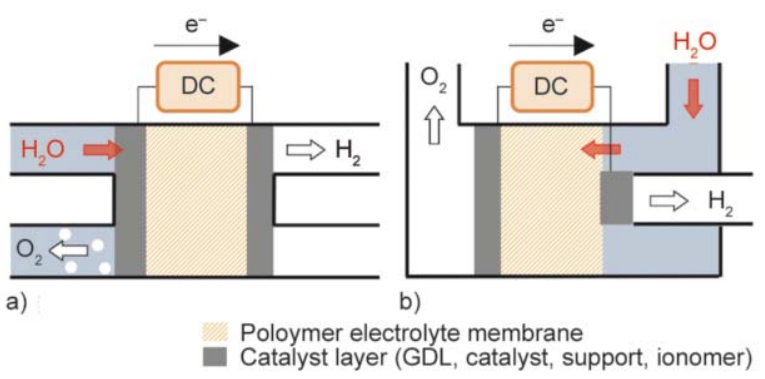

Figure 1. Schematic image of (a) conventional water electrolysis cell and (b) water-absorbing electrolyte cell. (a) Water is applied to GDL and water/gas mixture is collected. (b) Pressurized water is applied to water-absorbing electrolyte and only gases are collected from electrodes.

design. In this PEM system, water is supplied to the gas diffusion layer (GDL). Therefore, the GDL must have a mixture of both hydrophobic and hydrophilic properties in order to allow simultaneous transport of liquid water and gaseous oxygen to the anode.

On the other hand, we have developed a new water electrolysis system with an alternative water-supply mechanism (Figure 1b) [5]. In our water electrolysis system, pressurized water can be supplied to the electrode reaction zone via a porous hydrophilic electrolyte, rather than through the GDL. In this system, the catalyst layer and the GDL can be fully hydrophobic in order to effectively transport the generated hydrogen and oxygen, since the pressurized water can spontaneously force the gases to the gas outlet line. Our system has a particular advantage for space applications, since the spontaneous separation of gas and water by gravity that occurs in conventional electrolysis cells cannot be carried out in the microgravity conditions of space.

In addition, many different proton conductive materials that would never be considered in conventional water electrolyzers can be also applied in this system, because the required features of the electrolyte are porosity and hydrophilicity with proton conductivity. Therefore, not only PEMs, but also e.g. proton conductive metal oxides and proton conductive surface-modified nano particles can be used. In general, PEMs should have excellent gas separation properties to reduce gas crossover. However, in this system, the pressurized water can suppress gas crossover between the two hydrophobic electrodes, although suppression of gas crossover depends on thickness of electrolyte membranes and water pressure. Therefore, powdered proton conductive materials can be applied in this system, which are expected to be able to reduce the concentration overvoltage by improving water supply due to their increased hydrophilicity and porosity [5-7].

Although this water electrolysis cell provides many advantages, there are still several technical problems that must be resolved such as gas barrier property of GDL, improvement of catalyst and electrolyte performance and optimization of the cell setting. When we focus on the electrolytes of this electrolysis system, one of problems is degradation of the membrane, as the powdered materials detach from the rest of the membrane. In the previous work, powdered hydrous titania electrolytes were physically fixed in place by the use of Nafion as a polymer binder [5]. However, gradual degradation of the electrolyte membrane still occurred during operation. Here, to solve this problem, composite organic-inorganic membranes are developed with a cross-linked polymer network. The remarkable feature of the cross-linked film in this study is that the proton conducting inorganic material comprises the major component of the films, whilst the polymer matrix is the minor component. This ensures that the water-absorbing porous nature of the films is maintained.

In this study, we selected simple materials as a model system for our electrolysis cell to confirm that the principle of our water electrolysis system is correct. Proton conducting H-MFI-24 zeolite is used as the inorganic proton conducting porous material, and poly(vinyl alcohol) (PVA) is used as the cross-linkable polymer. Zeolites are well known as porous materials, and several have proton conducting properties $[8,9]$. PVA is well known as a water-soluble polymer, and many studies on zeolite-PVA composite films have been reported for various applications [10-15], and most of these studies utilized an aldehyde cross-linking reaction in acidic condition (Figure 2) $[15,16]$. Cross-linking of PVA can be carried out in thin film form, which is very important in this study, since the PVA can easily be cross-linked by penetration of the cross-linker aqueous solution after composite film preparation. In addition, the retained hydroxyl group of PVA matrix after cross-liking reaction is also attractive for water-absorbing electrolyte membranes because hydroxyl group would help water absorption in the membrane.

Here, as a first step of improvement of water-absorbing electrolyte membranes, we developed the crosslinked zeolite-PVA composite films and evaluated whether the cross-linked zeolite-PVA composite 


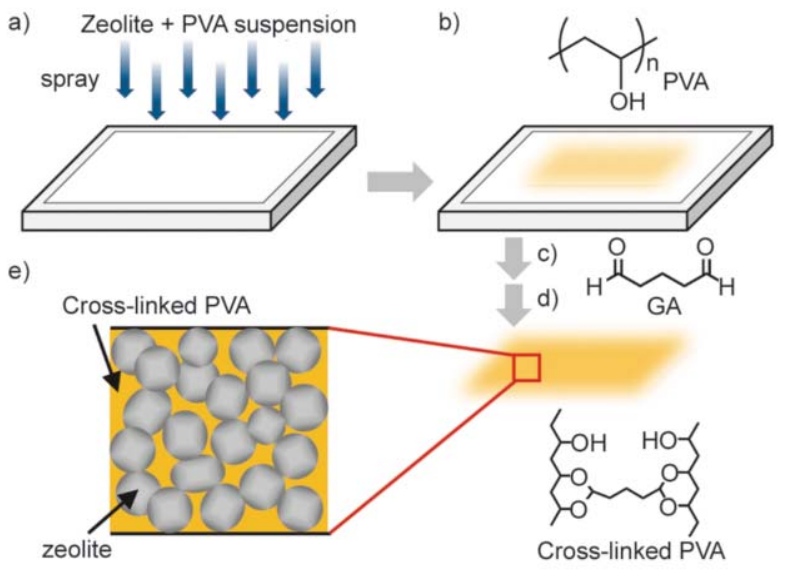

Figure 2. Flow chart for the fabrication of nano zeolite-PVA composite films. (a) Spraying nano zeolite and PVA aqueous suspension to PVDC film on flat glass. The glass was put on a hot plate $\left(100^{\circ} \mathrm{C}\right)$. (b) Drying process at $70^{\circ} \mathrm{C}$ for 1 hour. (c) Chemical cross-linking process. Film with PVDC substrate was immersed in $\mathrm{GA} / \mathrm{HCl}$ aqueous solution for 24 hours. (d) Washing process in hot water $\left(70^{\circ} \mathrm{C}\right)$ for 24 hours. (e) Cross section of nano zeolite-cross-linked PVA composite film.

films can work as the water-absorbing electrolyte membranes for our novel water electrolysis system. We discussed about the properties of the prepared films as the water-absorbing electrolyte membranes using primitive results obtained from our water electrolysis cell system.

\section{Experimental section \\ 2.1. Materials}

Proton-conducting zeolite (H-MFI-24, $\mathrm{H}_{2} \mathrm{Si}_{25} \mathrm{Al}_{2} \mathrm{O}_{54} \cdot \mathrm{nH}_{2} \mathrm{O}$ ) was provided by Prof. Satokawa. Fully hydrolyzed poly(vinyl alcohol) (PVA, $M_{\mathrm{w}}$ $60000,>98.0 \%$, Merck) was used without any purification. $25 \%$ glutaraldehyde aqueous solution (GA, Wako) and hydrochloric acid (35.0-37.0\%, Wako), acetylene black (AB, Denka Company Ltd.), polytetrafluoroethylene dispersion (PTFE) (Polyflon PTFE$\mathrm{D}, 60 \mathrm{wt} \%$ aqueous solution, Daikin Industries Ltd.), Triton-X (98\%, Kishida Chemical) were used as received. Micro-porous layer (MPL)-coated carbon paper (GDL29BC) and catalyst solution $\left(\mathrm{IrO}_{2}\right.$ and $\mathrm{Pt} /$ carbon) with Nafion suspension were purchased from CHEMIX, Japan. A Spray-Work HG Air Compressor was used with a wide airbrush (TAMIYA, Japan) for membrane deposition.

\subsection{Equipment}

Dynamic light scattering (DLS) was performed using a Zetasizer $\mu \mathrm{V}$ (Malvern Instruments Ltd), and the concentration of sample aqueous solution was about $0.05 \mathrm{wt} \%$. Fourier transform infrared spectroscopy (FT-IR) was performed using a Nicolet iN10 MX (Thermo Fisher Scientific K.K., Japan) with an ATR attachment. Thermogravimetric (TG) analysis was carried out on a Thermo Plus EVO2 (Rigaku, Japan). The experimental conditions used for $\mathrm{TG}$ were $10^{\circ} \mathrm{C} /$ min heating rate from 50 to $800^{\circ} \mathrm{C}$ in $\mathrm{N}_{2}$ atmosphere. Before increasing the temperature, samples were kept at $120^{\circ} \mathrm{C}$ for 20 min to remove adsorbed water in the films. The morphology of the obtained films and the starting materials was observed by FE-SEM (JSM-7001F, JEOL, Japan). The in-plane proton conductivity of the compressed zeolite was measured by four-probe impedance spectroscopy. Four Pt wires ( $0.1 \mathrm{~mm}$ of diameter) were attached to the compressed zeolite pellet by silver paste, and the impedance of the sample was measured in water at $95^{\circ} \mathrm{C}$ using an impedance analyzer (Versa STAT4, Princeton Applied Research Co. Ltd). The frequency range was $1 \mathrm{MHz}$ to $0.1 \mathrm{~Hz}$ with an applied voltage of $100 \mathrm{mV}$. For through-plane proton conductivity measurements of the composite films, 740 Membrane Test System (MTS, Scribner Associates, Inc.) was used with a through-plane measurement attachment (740 Cell Head) and a Solatron 1260 impedance meter (Solatron, UK) [17]. The current, voltage and frequency range used were $0.1 \mathrm{~mA}$, $1 \mathrm{~V}$ and $10-10^{6} \mathrm{~Hz}$, respectively. The samples were compressed between gas diffusion electrodes that were attached to solid platinum backing electrodes with conductive carbon paint. The samples were conditioned for $2 \mathrm{~h}$ at $95 \% \mathrm{RH}$ and each temperature.

\subsection{Milling of zeolite}

Milling of the zeolite powder was carried using a planetary milling machine (Pulverisette7, Fritsch Japan Co., Ltd, Japan). Zirconia beads of 2 and $0.05 \mathrm{~mm}$ were used for the milling, and water was used as a dispersion medium. Zeolite H-MFI-24, water and $2 \mathrm{~mm}$ zirconia beads were placed into $45 \mathrm{~mL}$ zirconia pot, and were planetary-milled at $500 \mathrm{rpm}$ for 1 hour, forming a white slurry. The slurry was separated by a sieve from the zirconia beads, 
and was transferred into the zirconia pot again with $0.05 \mathrm{~mm}$ zirconia beads, then milled at $800 \mathrm{rpm}$ for 7 hours. The final nano zeolite aqueous solution was obtained after separation of zirconia beads.

\subsection{Film preparation}

The typical preparation process of zeolite-PVA composite films is described here. $1.7 \mathrm{~mL}$ of the milled zeolite aqueous solution ( $5 \mathrm{wt} \%$ ) was mixed with $1.063 \mathrm{~mL}$ of $20 \mathrm{mg} / \mathrm{mL}$ PVA aqueous solution, and $1.488 \mathrm{~mL}$ of water. The mixture was sprayed onto PVDC film on flat glass (heater temperature: $100^{\circ} \mathrm{C}$ ). After spraying, the film was dried at $70^{\circ} \mathrm{C}$ for 1 hour. The dried film was immersed in $1.0 \mathrm{M} \mathrm{GA}$ and $0.3 \mathrm{M}$ $\mathrm{HCl}$ aqueous solution for 24 hours at room temperature, for chemical cross-linking of PVA and GA. After immersion, the obtained film was washed by water thoroughly, then immersed in hot water $\left(70^{\circ} \mathrm{C}\right)$ for 24 hours. The thickness of the wet film was $45 \mu \mathrm{m}$. The prepared zeolite-PVA composite film was stored in humidified conditions to prevent crack formation.

\subsection{MEA preparation and water electrolysis by water-absorbing electrolyte cell}

Water electrolysis was carried out using the waterabsorbing electrolyte cell shown in Figure 1b. As a GDL layer, hydrophobic GDL was prepared. $2.0 \mathrm{~g}$ of acetylene black (AB) powder was dispersed in $1.0 \mathrm{~g}$ of Triton-x as a surfactant, $95 \mathrm{~mL}$ of water and $5 \mathrm{~mL}$ of ethanol for $15 \mathrm{~min}$ at room temperature. After sonication, the mixture was milled by a rolling machine for 24 hours at room temperature, with zirconia beads of $2.0 \mathrm{~mm} .5 \mathrm{~g}$ of PTFE was mixed with the $\mathrm{AB}$ mixture, and the mixture was milled again for 1 hour at room temperature. The obtained mixture was filtered, and an AB/PTFE slurry was obtained. The prepared slurry was sprayed to $180 \mathrm{~mm} \times 180 \mathrm{~mm}$ aluminum foil on $200^{\circ} \mathrm{C}$ hot plate. The sprayed mixture was dried under vacuum at $200^{\circ} \mathrm{C}$ for $15 \mathrm{~min}$ to remove all solvents.

The dried mixture was attached to the mesoporous layer (MPL) of a carbon paper (CP). The assembled MPL-CP with AB/PTFE was pressed at $240 \mathrm{~kg} / \mathrm{cm}^{2}$ for 3 min at $360{ }^{\circ} \mathrm{C}$. The MPL-CP with $\mathrm{AB} / \mathrm{PTEF}$ was immersed into $6 \mathrm{wt} \% \mathrm{HCl}$ aqueous solution to completely remove the aluminum foil substrate. The MPL-CP with AB/PTEF as a hydrophobic GDL was washed by water thoroughly and dried at room temperature.
Catalyst solution was pasted onto the prepared hydrophobic GDL. $\mathrm{IrO}_{2}$ and $\mathrm{Pt}$ were used as anode and cathode catalysts, respectively. The catalyst loadings of $\mathrm{IrO}_{2}$ and $\mathrm{Pt}$ were 1.5 and $0.5 \mathrm{mg} / \mathrm{cm}^{2}$, respectively. In the catalyst layer, $1.3 \mathrm{mg} / \mathrm{cm}^{2}$ of carbon was also used as a catalyst support. The zeolite-PVA composite film $(45 \mu \mathrm{m})$ was placed on the obtained electrode, and the other electrode was placed on the composite film. The membrane/electrode assembly (MEA) was then pressed to form the electrolysis cell. In this study, water was supplied to zeolite-PVA membrane at $0.03 \mathrm{MPa}$. The cell temperature was $95^{\circ} \mathrm{C}$. Current was supplied to the cell using a galvanostat (Hokuto Denko Co., Potentiostat/Galvanostat HA-151B). The generated hydrogen was detected by gas chromatography (GC, Agilent Technologies CO. Ltd, Micro GC 3000A, column: Molsieve, $14 \mathrm{~m} \times 320 \mu \mathrm{m} \times 12 \mu \mathrm{m})$. The flow gas used was $\mathrm{Ar}$ $(20 \mathrm{~mL} / \mathrm{min})$.

\section{Results and discussion}

Zeolite-PVA composite film preparation was performed using a spray deposition method (Figure 2) [18]. Spray deposition results in a more homogenous composite film compared to the solvent cast method, since the relatively dense zeolite particles tend to agglomerate at the underside of the film when drying solvent-casted films. A proton conducting H-MFI-24 zeolite $\left(\mathrm{SiO}_{2} / \mathrm{Al}_{2} \mathrm{O}_{3}\right.$ molar ratio $\left.=24\right)$ was selected for use in this study. The in-plane proton conductivity of compressed as-received zeolite pellets was $3 \mathrm{mS} / \mathrm{cm}$ at $95^{\circ} \mathrm{C}$ in water. Compared to the conventional electrolyte such as Nafion, the proton conductivity of this zeolite was low. However, we used this zeolite as a model proton conductive material in this study. The zeolite powder was ground by ball milling to make zeolite particles with an average diameter of less than $1 \mu \mathrm{m}$, and the mean diameter of the ground zeolite particles was $190 \mathrm{~nm}$, as measured by dynamic light scattering (DLS) (Figure 3). This milling process is important in this study, because large secondary aggregates of zeolite particles would weaken the stabilizing effect of the polymer network, leading to particle detachment. Moreover, particles with $>\mu \mathrm{m}$ size are not suitable for spraying, since larger particles can block the nozzle of the air brush.

The electrolyte membrane for our electrolysis cell design should contain a high proportion of porous electrolytes, as well as being mechanically stable. In order to optimize this material design, we prepared 


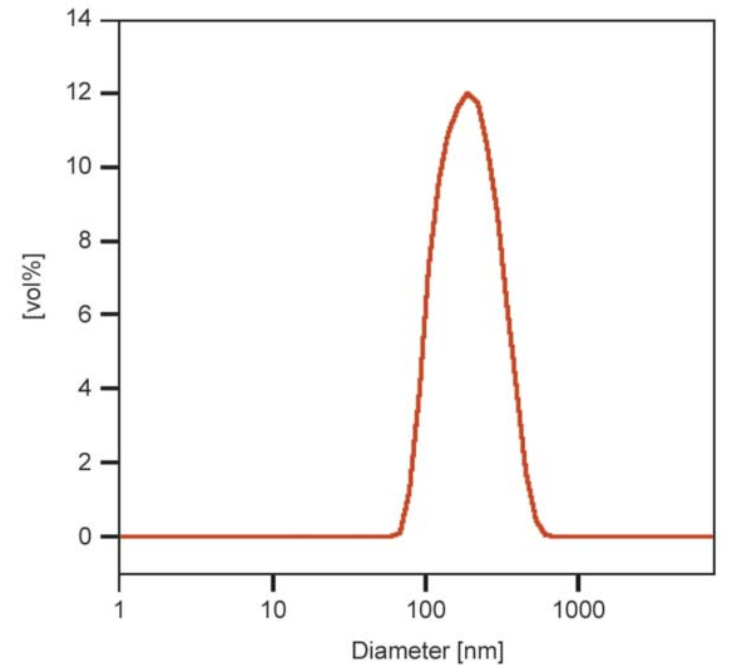

Figure 3. DLS of ground zeolite. DLS of zeolite without milling process was not obtained because of precipitation

several zeolite-PVA films with different weight ratios. During the spraying process, small cracks were generally observed in the composite films after drying, whist the overall shape was maintained. As suitable ratio of zeolite: PVA, zeolite: PVA $=8: 2$ [wt\%] was used in this study. Composite films with a thickness of around $40 \mu \mathrm{m}$ were prepared by spraying using these proportions.

The obtained composite films were immediately immersed in glutaraldehyde (GA) cross-linker solution. The cross-linking reaction between PVA and GA was confirmed by several experimental techniques. After the cross-linking reaction, the composite film was washed in hot water $\left(70^{\circ} \mathrm{C}\right)$ for 24 hours. In the case that PVA and GA did not react with each other, the thin composite films would be expected to readily dissolve in hot water. However, since the composite films did not dissolve (Figure 4, inset), this is indirect evidence that the cross-linking reaction was successful. FT-IR also supports that the cross-linking reaction was successful (Figure 5). In the IR spectra of PVA and cross-linked PVA, a broad band was observed from $3600-3000 \mathrm{~cm}^{-1}$, assigned to $-\mathrm{OH}$ stretching of PVA [18]. The peak wavenumber of this band is at $3286 \mathrm{~cm}^{-1}$ for PVA, and at $3424 \mathrm{~cm}^{-1}$ for cross-linked PVA. The peak shift to large wavenumber by the retained hydroxyl group in cross-linked PVA is the same as the reported study [18]. On the other hand, the zeolite-PVA films after the crosslinking reaction also displayed a broad band in the same region, with a peak at $3366 \mathrm{~cm}^{-1}$. Before crosslinking, the zeolite-PVA films have an $-\mathrm{OH}$ peak with a smaller wavenumber $\left(3292 \mathrm{~cm}^{-1}\right)$ than the

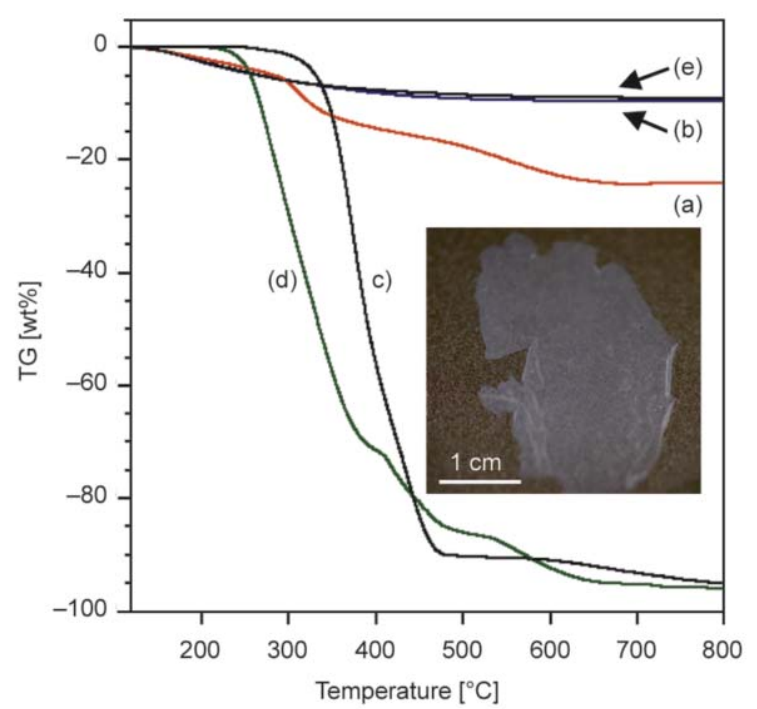

Figure 4. TG results of (a) zeolite: PVA $=8: 2[\mathrm{wt} \%]$ composite film, (b) zeolite, (c) cross-linked PVA, (d) PVA and (e) zeolite after cross-link treatment. Inset was photo of zeolite: PVA $=8: 2[\mathrm{wt} \%] \mathrm{com}-$ posite film $(42 \mu \mathrm{m})$.

cross-linked film. This indicates that the cross-linking reaction of PVA by GA was successful in the zeolite-PVA composite films.

In order to confirm the weight ratio of zeolite and PVA in the composite film after the cross-linking reaction, thermogravimetry (TG) was performed on the composite film (Figure 4). In order to suppress the effect of excess physisorbed water in the composite films, all samples were heated at $120^{\circ} \mathrm{C}$ for $20 \mathrm{~min}$ in nitrogen atmosphere before the TG measurements. Up to $300^{\circ} \mathrm{C}$, the composite film after cross-linking (Figure 4 curve a) and the pure zeolite

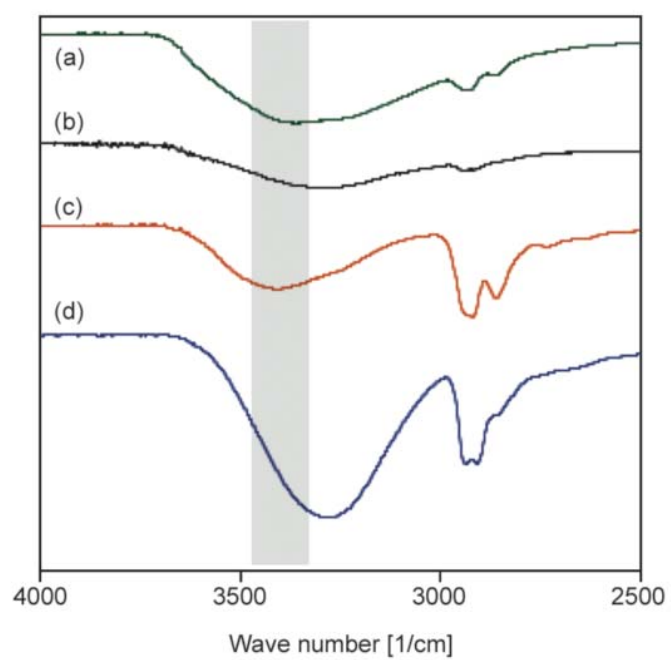

Figure 5. FT-IR spectra of (a) zeolite-cross-linked PVA, (b) zeolite-PVA before cross-linking reaction, (c) cross-linked PVA and (d) intact PVA 
(Figure 4 curve b) show gradual weight loss. On the other hand, cross-linked PVA without zeolite did not show any weight loss up to $300^{\circ} \mathrm{C}$ (Figure 4 curve c). Although physisorbed water in the films was removed at $120^{\circ} \mathrm{C}$, more tightly bound (possibly chemisorbed) water remains in the zeolite and the zeolitePVA composite film. Therefore, the composite film and zeolite which have similar weight loss up to $300^{\circ} \mathrm{C}$, have a similar amount of tightly bound water in the zeolite.

The decomposition temperature of PVA in the composite film also supports that the cross-linking reaction of PVA proceeded successfully. The onset of decomposition in cross-linked PVA starts at $300^{\circ} \mathrm{C}$, while standard PVA starts to decompose at the lower temperature of $250^{\circ} \mathrm{C}$. This result indicated that cross-linked network structure of PVA would suppress the thermal decomposition of PVA. The final weight loss of zeolite was 9.5\% (Figure 4 curve b). The weight ratio of PVA in the composite film was $14.3 \%$, although the initial weight ratio of PVA before cross-linking was $20 \%$. This slight difference indicates that some of the non-reacted PVA would be washed out from the composite film. This data can

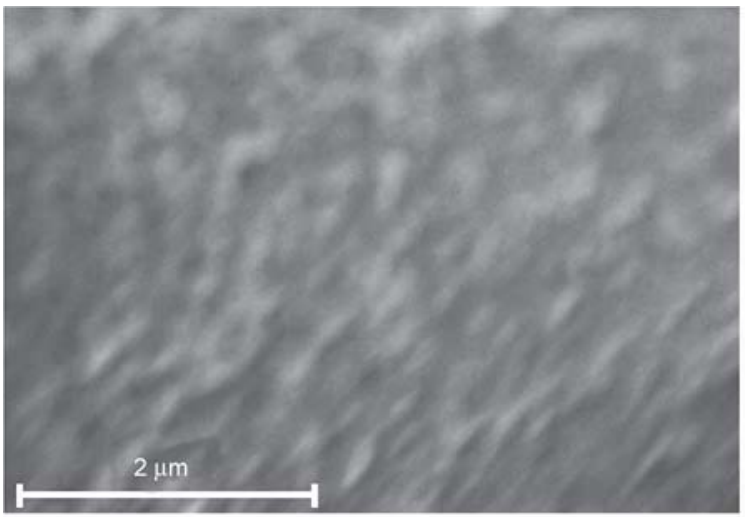

a)

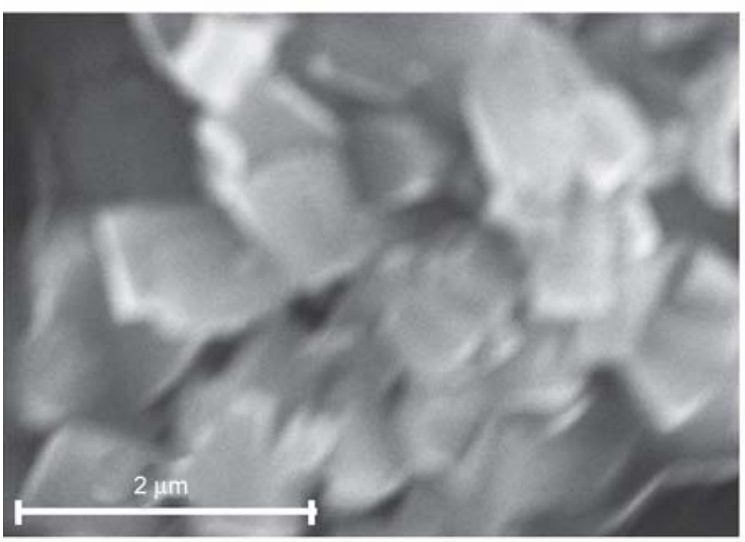

c) also be used to confirm if any cross-linking reaction occurred between the zeolite and the GA, since the zeolite also has hydroxyl groups on the surface. However, after mixing the zeolite and the GA without PVA, the TG curve of this mixture is unchanged, indicating that no reaction took place between the zeolite and GA (Figure 4 curve e).

The morphology of the zeolite-PVA composite film was observed by FE-SEM (Figure 6a). Compared to a cross-linked PVA film without zeolite (Figure 6d), the surface structure of the composite film was very rough, with feature sizes of several hundred $\mathrm{nm}$. This roughness clearly originates from the ground zeolite particles (Figure 6b). The morphology of the zeolitePVA composite film indicates that the PVA network is thinly coated on/between the ground zeolite particles, since the major component of the composite films is zeolite. The reason that such a high concentration of zeolite in the composite film is possible was that the PVA network could contribute to the stability of the film, due to the small size $(<100 \mathrm{~nm})$ of the zeolite particles. In contrast, the intact zeolite is $\mu \mathrm{m}$ scale particles and thus stable films could not easily be formed (Figure $6 \mathrm{c}$ ). The above results confirm

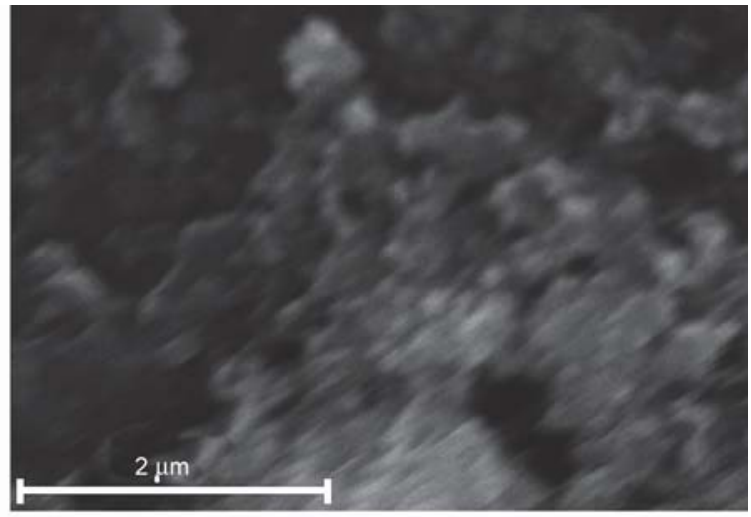

b)

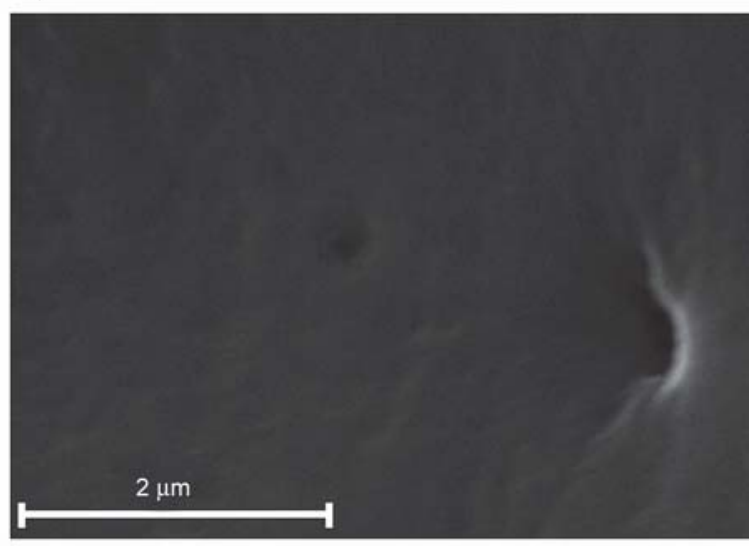

d)

Figure 6. FE-SEM of (a) zeolite: PVA = 8:2 [wt \%] composite film, (b) zeolite after milling, (c) zeolite without milling, and (d) cross-linked PVA 
that the ground zeolite particles are distributed homogeneously in the composite films, and that the PVA network is covered on the surface of these zeolite particles, contributing to the formation of stable films. One of the important functions of these composite films is to enhance water uptake in the electrolyte. The properties of the composite film as a water-absorbing electrolyte were therefore investigated. The water uptake of the composite film was $50 \%$, compared to $26 \%$ for Nafion 212 under the same conditions. This result confirms that the porous zeolite does indeed act to promote water-absorption in the membranes.

The through-plane proton conductivity of the composite films was measured (Figure 7). The proton conductivity at $100{ }^{\circ} \mathrm{C}$ and $95 \%$ relative humidity (RH) was $2.8 \mathrm{mS} / \mathrm{cm}$. Compared to Nafion $(\sim 100 \mathrm{mS} / \mathrm{cm})$, the proton conductivity of the composite film is relatively low. This is attributed to the low conductivity of the zeolite powder $\left(3 \mathrm{mS} / \mathrm{cm}\right.$ at $95^{\circ} \mathrm{C}$ and $100 \%$ $\mathrm{RH})$. The proton conductivity of the composite film is similar to that of the zeolite powder, as expected. The proton conductivities of the pure zeolite powder and the zeolite:PVA $=8: 2[\mathrm{wt} \%]$ composite are similar, despite using different experimental set ups, because the amount of PVA was low. We will perform more precise proton conductivity measurements using optimized samples in future work. In addition, the obtained conductivity results support that the zeolite

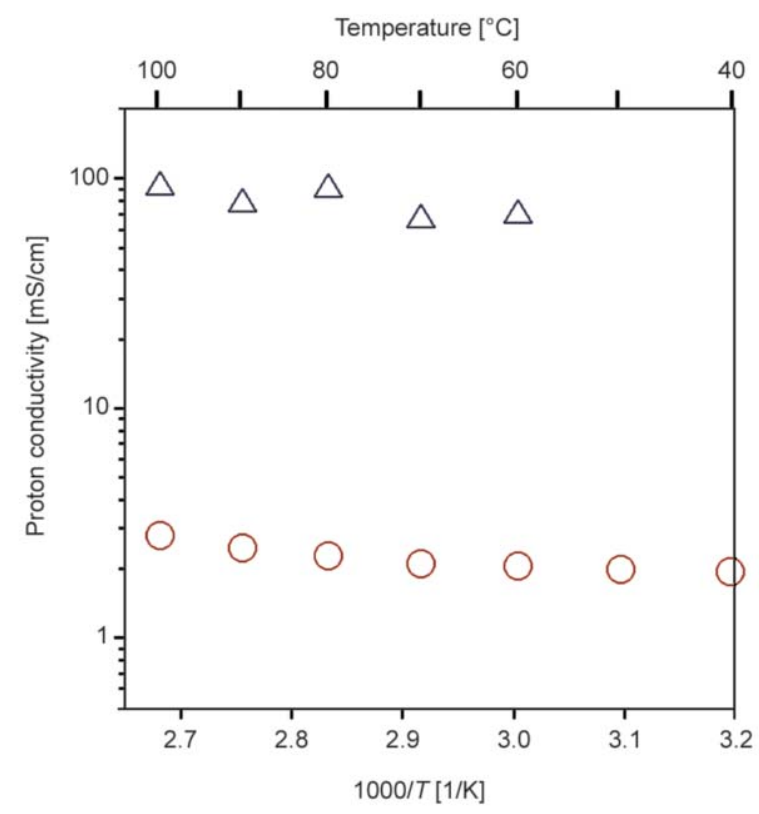

Figure 7. Proton conductivity of zeolite: PVA $=8: 2[\mathrm{wt} \%]$ composite film (circle), Nafion 212 (triangle) at 95\% RH\%. and GA did not cross-link with each other because the acidic hydroxyl group in the zeolite powder could act as a weak proton conductor. The obtained activation energy of the composite film for proton conductivity at $95 \% \mathrm{RH}$ was $6.6 \mathrm{~kJ} / \mathrm{mol}$. Since the zeolite and PVA do not have strong acidic functional groups in this study, and the measurements were performed at high humidity $(95 \% \mathrm{RH})$, the proton conduction mechanism is likely to be vehicular. These results indicate that the zeolite-PVA composite film could be used as an electrolyte membrane in a waterabsorbing water electrolysis cell.

Finally, to confirm that our material design was justified, we evaluated the properties of the zeolite-PVA composite film for water electrolysis, using the waterabsorbing electrolyte cell design (Figure 8). A membrane-electrode assembly (MEA) was prepared using the zeolite-PVA composite electrolyte membrane, Nafion as an ionomer and $\mathrm{IrO}_{2}$ and $\mathrm{Pt}$ as an electrocatalyst at the anode and cathode both supported on the GDL. From the I-V curve of the prepared MEA, a potential of $1.8 \mathrm{~V}$ for water electrolysis was confirmed, with $45 \mathrm{~mA} / \mathrm{cm}^{2}$ current density (Figure 8a). Hydrogen evolution was also confirmed with a yield of $66 \%$ from the theoretical value, at $18 \mathrm{~mA} / \mathrm{cm}^{2}$ (Figure $8 \mathrm{~b}$ ). These results are lower than that of the conventional water electrolysis system and not sufficient for the practical application. The reason of low performance is that total IR loss became large since proton conductivity of the zeolite-PVA composite film was low, and the cell setup such as insufficiency of the mechanical gas sealing between the outlet gas line and the GDL was not optimized yet. However, the zeolite-PVA composite film showed

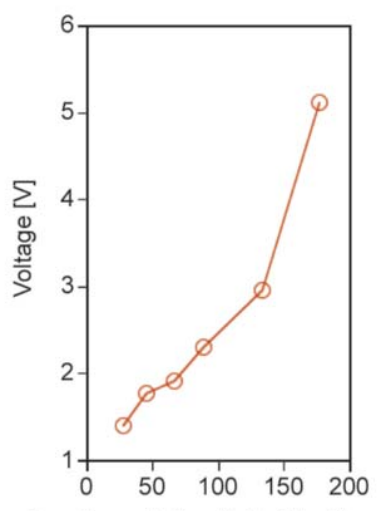

a) Current density $\left[\mathrm{mA} / \mathrm{cm}^{2}\right]$

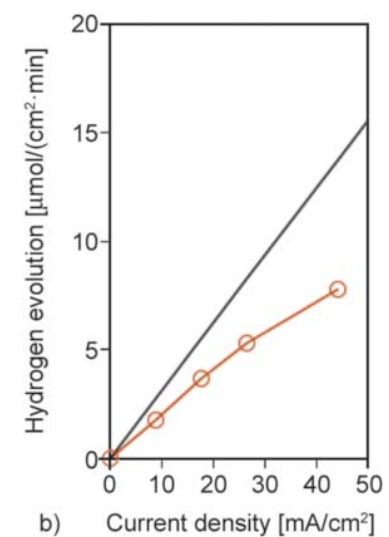

Figure 8. Water electrolysis performance (a) and hydrogen evolution (b) of water-absorbed electrolyte cell at $95^{\circ} \mathrm{C}$. Solid line in (b) was theoretical amount of hydrogen evolution 
water electrolysis performance, although the value was low. It indicates that proton conductive zeolite can work as the water-absorbing electrolyte in crosslinked PVA matrix which is hydrophobic and not proton conductive. This result suggested that the material design for this water electrolysis cell was justified by a model system of zeolite and PVA. Low yield of hydrogen evolution is the future subject of this water electrolyte system. In this work, water pressure was only $0.03 \mathrm{MPa}$ because the gas sealing between the outlet gas line and the GDL and water barrier property of GDL were not enough. Therefore, some of the generated gases could not move to the outlet gas line effectively. Low water pressure might cause the crossover of the gases, and some of gases would move to the water chamber for the electrolyte from the sealing part between the outlet gas line and the GDL. Currently, to increase the water pressure and improve yield of hydrogen evolution, we also develop the sealing system and the GDL with high barrier property to pressurized water in parallel and try to prove that the pressurized water can suppress the gas crossover during operation of the water electrolysis using our water electrolysis cell.

Important point of this work is that we confirmed that conventional model materials such as zeolites and PVA could be used for the water electrolysis as an electrolyte, and the principle of our water electrolysis system was correct, although at present the performance was not high enough for practical applications. In this study, the intact zeolite was used and not modified on the surface. Therefore, proton conductivity of the electrolyte would be able to be improved by surface modification of the electrolyte materials which are cheaper than Nafion. On the basis of the results in zeolite-PVA system, we develop more effective water-absorbing electrolyte membranes for this water electrolysis system such as high proton conductive nano particles with PVA matrix.

\section{Conclusions}

In this study, we developed a water-absorbing electrolyte membrane consisting of proton conducting zeolite with a PVA polymer matrix as model materials to confirm that the concept of a water-absorbing electrolyte for a novel water-absorbing porous electrolyte water electrolysis cell was correct. The zeolite-PVA composite films ware prepared by spraying onto a substrate, followed by cross-linking. Although the performance of the composite film was not high enough for practical applications, it was confirmed that zeolites and PVA as model materials could be used for the water electrolysis, and the concept of a water-absorbing electrolyte was correct. The waterabsorbing electrolytes for the water-absorbing porous electrolyte cell have different features from conventional electrolyte membranes. Thus, many materials that that are not suitable to be used in conventional water electrolysis can now be applied.

\section{Acknowledgements}

This work was supported by CREST (Creation of Innovative Core Technology for Manufacture and Use of Energy Carriers from Renewable Energy), JST, Japan, and 'Center of Innovation Science and Technology based Radical Innovation and Entrepreneurship Program (COI Program)', JST Japan.

\section{References}

[1] Sasaki K., Li H-W., Hayashi A., Yamabe J., Ogura T., Lyth S. M.: Hydrogen energy engineering. A Japanese perspective. Springer, Tokyo (2016). https://doi.org/10.1007/978-4-431-56042-5

[2] He T., Pachfule P., Wu H., Xu Q., Chen P.: Hydrogen carriers. Nature Reviews Materials, 1, 1-17 (2016). https://doi.org/10.1038/natrevmats.2016.59

[3] Møller K. T., Jensen T. R., Akiba E., Li H-W.: Hydrogen - A sustainable energy carrier. Progress in Natural Science: Materials International, 27, 34-40 (2017). https://doi.org/10.1016/j.pnsc.2016.12.014

[4] Carmo M., Fritz D. L., Mergel J., Stolten D.: A comprehensive review on PEM water electrolysis. International Journal of Hydrogen Energy, 38, 4901-4934 (2013).

https://doi.org/10.1016/j.ijhydene.2013.01.151

[5] Kim S-J., Sakai T., Oda H., Hamagami J-I., Okuyama Y., Matsuka M., Ohta S., Shimizu Y., Ishihara T., Matsumoto H.: Water electrolysis using water-absorbing porous electrolyte consisting of a sulfonated nanotitania proton conductor. Electrochemistry, 80, 246-248 (2012). https://doi.org/10.5796/electrochemistry.80.246

[6] Sakai T., Kim S-J., Kajitani S., Hamagami J-I., Oda H., Matsuka M., Ishihara T., Matsumoto H.: Proton conduction properties of nano-titania modified by sulfuric acid impregnation. Journal of Solid State Electrochemistry, 16, 2055-2059 (2012).

https://doi.org/10.1007/s10008-011-1616-0

[7] Jun Y., Zarrin H., Fowler M., Chen Z.: Functionalized titania nanotube composite membranes for high temperature proton exchange membrane fuel cells. International Journal of Hydrogen Energy, 36, 6073-6081 (2011). https://doi.org/10.1016/j.ijhydene.2011.02.030 
[8] Kreuer K. D., Weppner W., Rabenau A.: Proton conduction in zeolites. Materials Research Bulletin, 17, 501-509 (1982).

https://doi.org/10.1016/0025-5408(82)90106-4

[9] Oesten R., Huggins R. A.: Proton conduction in oxides: A review. Ionics, 1, 427-437 (1995).

https://doi.org/10.1007/BF02375287

[10] Khoonsap S., Amnuaypanich S.: Mixed matrix membranes prepared from poly(vinyl alcohol) (PVA) incorporated with zeolite 4A-graft-poly(2-hydroxyethyl methacrylate) (zeolite- $g$-PHEMA) for the pervaporation dehydration of water-acetone mixtures. Journal of Membrane Science, 367, 182-189 (2011).

https://doi.org/10.1016/j.memsci.2010.10.058

[11] Teli S. B., Calle M., Li N.: Poly(vinyl alcohol)-H-ZSM5 zeolite mixed matrix membranes for pervaporation separation of methanol-benzene mixture. Journal of Membrane Science, 371, 171-178 (2011).

https://doi.org/10.1016/j.memsci.2011.01.033

[12] Roushan A. H., Omrani A., Kavian S., Azizi S. N.: Determination of degradation kinetics of polyvinyl alcohol/X-zeolite nanocomposite. Journal of Thermal Analysis and Calorimetry, 128, 1057-1066 (2017). https://doi.org/10.1007/s10973-016-5998-1

[13] Amirilargani M., Sadatnia B.: Poly(vinyl alcohol)/zeolitic imidazolate frameworks (ZIF-8) mixed matrix membranes for pervaporation dehydration of isopropanol. Journal of Membrane Science, 469, 1-10 (2014). https://doi.org/10.1016/j.memsci.2014.06.034
[14] Huang Z., Guan H-M., Tan W. L., Qiao X-Y., Kulprathipanja S.: Pervaporation study of aqueous ethanol solution through zeolite-incorporated multilayer poly (vinyl alcohol) membranes: Effect of zeolites. Journal of Membrane Science, 276, 260-271 (2006).

https://doi.org/10.1016/j.memsci.2005.09.056

[15] Higa M., Feng S., Endo N., Kakihana Y.: Characteristics and direct methanol fuel cell performance of polymer electrolyte membranes prepared from poly(vinyl alcohol- $b$-styrene sulfonic acid). Electrochimica Acta, 153, 83-89 (2015). https://doi.org/10.1016/j.electacta.2014.11.155

[16] Rudra R., Kumar V., Kundu P. P.: Acid catalysed crosslinking of poly vinyl alcohol (PVA) by glutaraldehyde: Effect of crosslink density on the characteristics of PVA membranes used in single chambered microbial fuel cells. RSC Advances, 5, 83436-83447 (2015). https://doi.org/10.1039/C5RA16068E

[17] Si K., Wycisk R., Dong D., Cooper K., Rodgers M., Brooker P., Slattery D., Litt M.: Rigid-rod poly (phenylenesulfonic acid) proton exchange membranes with cross-linkable biphenyl groups for fuel cell applications. Macromolecules, 46, 422-433 (2013). https://doi.org/10.1021/ma301875n

[18] Breitwieser M., Bayer T., Büchler A., Zengerle R., Lyth S. M., Thiele S.: A fully spray-coated fuel cell membrane electrode assembly using Aquivion ionomer with a graphene oxide/cerium oxide interlayer. Journal of Power Sources, 351, 145-150 (2017). https://doi.org/10.1016/j.jpowsour.2017.03.085 